\title{
Research on the Sensitivity Assessment of Soil Erosion by AHP Method: A Case Study in the Northeast of Ordos Basin
}

\author{
Wang $\mathrm{Wei}^{1}$, Chen Sheming ${ }^{1 *}$, Zhu Lin $^{2}$, Meng Lishan ${ }^{1}$, Cheng Rui ${ }^{2}$, Liu Futian ${ }^{1}$ \\ ${ }^{1}$ Tianjin Center, China Geological Survey,Tianjin 300170, China \\ ${ }^{2}$ College of Resources Environment and Tourism,Capital Normal University,Beijing 100048,China
}

\begin{abstract}
The ecological environment of Northeastern Ordos Basin which located in the Northwestern China belongs to arid and semi-arid area. The hazards of water and soil loss here are serious caused by gully river erosion. Since Soil erosion is an important factor leading to the destruction of regional ecology and has a profound impact on the long-term and healthy development of the economy and society, it is necessary to do research on the sensitivity analysis about soil erosion. In this study, the AHP (Analytic Hierarchy Process) method was used to determine the index weight of the factors for soil erosion, and made it more consistent with the whole regional condition. The results demonstrated that the soil medium, slope and vegetation coverage had the highest influence on soil erosion under the same climatic and meteorological conditions in the study area. This research evaluated the sensitivity factors and provided a significant guidance for soil erosion control.
\end{abstract}

\section{Introduction}

The Ordos region is an important energy and chemical industry base for the coexistence of multiple energy sources such as oil, gas, coal, and uranium in China[1-2]. The region belongs to arid and semi-arid areas, the ecological environment is fragile, and the intensity of soil and water loss range is large, its form is mainly erosion of gully river. Soil erosion is an important factor leading to the destruction of regional ecological environment, and has a profound impact on the longterm and healthy development of the economy and society. In the past, the related research work on water loss in Ordos area mainly focused on the prevention and control of soil erosion, such as the use of vegetation[3-7], construction of water conservancy facilities, and soil modification[8], and put forward some countermeasures[9-10].In the past, most of the work was carried out on regional or specific land types[4,6], which lacked systematicity and integrity, and it is difficult to provide a systematic basis and reference for regional water, land resources protection and urban planning .So in this research, the northeastern area of Ordos was taken as a typical research area .According to the data obtained from the field survey in 2015-2017, the regional evaluation research work was carried out. In the research area, the surface erosion is strong, the gullies are developed, and there are many mines, the typical research area also covers the main urban areas of Ordos. Carrying out the regional soil erosion sensitivity assessment is of great significance to regional social and economic development and ecological environmental protection.

\section{Evaluation system of soil erosion sensitivity based on AHP method}

\subsection{Analytic Hierarchy Process (AHP)}

The AHP method is a combination of qualitative and quantitative decision analysis method, it's the decision makers who follow the decision-making process, to model and quantify the decision process of complex system [11]. Decision makers decompose a multi-level and multi-criteria complex problems into several levels and several constituent factors, and groups these factors into governing relationships to form an ordered hierarchy[11], the relative importance of each factor in the hierarchy is determined by pairwise comparison, then the order of importance is determined comprehensively.

This study fully analyses the geological environment conditions, distribution characteristics and main influencing factors of the formation and development of soil erosion in the study area. On the basis of the previous research to select a reasonable evaluation index. The analytic hierarchy process (AHP) was selected to determine the index score and weight, the comprehensive evaluation model of soil erosion was established to comprehensively calculate the index of soil erosion sensitivity in the research area .Based on this, the soil erosion sensitivity in the study area was evaluated. The main evaluation standards refer to " Technical code of practice on water and soil conservation monitoring (SL277--2002)” , “Standards for Classification and gradation for soil erosion (SL190-

\footnotetext{
*Corresponding author: tjdzdczx2013@126.com
} 
2007)" , "Classification standards for potential hazard of soil erosion (s1718-2015)” .

\subsection{The selection of soil erosion evaluation factors}

The soil erosion in the study area is the result of the interaction of natural factors and human factors[12], it is affected by water and wind erosion for a long time, coupled with human mining areas, urban expansion and other active factors .According to the unique geological environment conditions and characteristics of soil erosion in northeastern Ordos, combined with the results of field investigations in the study area, the factors directly related to the soil erosion and the dominant factor were selected as evaluation factors, which is the key to evaluate the vulnerability of soil erosion. The natural factors include the type of geomorphologic , gully density, soil medium, vegetation coverage, rainfall intensity, etc .Human factors include mine development, land use type, water and soil conservation management level, etc. Due to the limited scope of the study area, the meteorological factors such as rainfall intensity and wind intensity did not change much, so the evaluation results were not affected. Gully density is to some extent the external manifestation of topographic slope, and topographic slope data comes from remote sensing interpretation, the data has high precision and can be quantified, so the topographic slope is mainly considered this time. The current management level of soil and water conservation is greatly influenced by policies factor. Moreover, the research area is the core region of Ordos city, and the intensity of ecological protection was almost the same in the region, which did not affect the evaluation results. In summary, according to the unique conditions and characteristics of this region, vegetation coverage, soil medium, geomorphic type, topographic slope and land use type were selected as evaluation factors in this study.

\subsubsection{Vegetation coverage}

Fractional Vegetation Cover (FVC) is extracted by using remote sensing technology in this research, which has a direct effect on desertification and soil erosion. Fractional Vegetation Cover is an important parameter, representing the percentage of vegetation vertical projection area and ground surface area. FVC is of great significance for the evaluation of regional ecological environment, and has great significance to the evaluation of regional ecological environment. According to the actual situation of the research area, the scores of different vegetation cover types were determined, as shown in table 1 .

Table 1. FVC grading and rating standards

\begin{tabular}{cccccc}
\hline $\begin{array}{l}\text { Vegetation } \\
\text { cover } \\
\text { types }\end{array}$ & $\begin{array}{c}\text { FVC } \\
\text { high }\end{array}$ & $\begin{array}{c}\text { FVC } \\
\text { medium }\end{array}$ & $\begin{array}{c}\text { FVC } \\
\text { Medium } \\
\text { to low }\end{array}$ & $\begin{array}{c}\text { FVC } \\
\text { low }\end{array}$ & $\begin{array}{c}\text { Bare land, } \\
\text { building land } \\
\text { and others }\end{array}$ \\
\hline $\begin{array}{c}\text { FVC } \\
\text { grading }\end{array}$ & $\begin{array}{c}> \\
70 \%\end{array}$ & $70-50 \%$ & $50-30 \%$ & $\begin{array}{c}30- \\
15 \%\end{array}$ & $<15 \%$ \\
\hline
\end{tabular}

\begin{tabular}{cccccc}
\hline $\begin{array}{c}\text { Rating } \\
\text { standards }\end{array}$ & 20 & 40 & 60 & 80 & 100 \\
\hline
\end{tabular}

\subsubsection{Soil medium}

The thickness of quaternary strata in the hilly zone of the study area is generally small, usually $0-2$ meters, and the surface soil is mainly sandy and sandy loam, and some areas have thin layer loess distribution. The gullies are mostly composed of various types of sand and gravel sand; The surface lithology of base rock outcrop area is mainly weathered sandstone and mudstone. The desert area is dominated by semi-mobile sand dunes and sandy land, and the surface is covered with aeolian sand. The influence of surface soil media on soil erosion is mainly reflected in the total porosity, particle size distribution, clay content and initial water content of soil[13].The higher soil porosity and the lower clay content, the more soil erosion occurs. In this study, based on the corrosion resistance of soil media and field investigation results, soil media were graded and assigned values, the rating table is shown in table 2 .

Table 2.Soil type grading and rating standards

\begin{tabular}{lc}
\hline \multicolumn{1}{c}{ Soil type } & $\begin{array}{c}\text { rating } \\
\text { standards }\end{array}$ \\
\hline $\begin{array}{l}\text { Eolian sand (refers to loose dry sand soil with a certain } \\
\text { thickness in the study area) }\end{array}$ & 100 \\
$\begin{array}{l}\text { Gravel, coarse sand, sandstone, medium sand, bedrock } \\
\text { weathering crust, medium coarse gravel, gravel }\end{array}$ & 50 \\
$\begin{array}{l}\text { Silty soil, muddy powdery sand, fine sand, powdery } \\
\text { sand, silty sand }\end{array}$ & 80 \\
$\begin{array}{l}\text { Sandy mudstone and mudstone interbedded, coal seam, } \\
\text { mudstone }\end{array}$ & 40 \\
$\begin{array}{l}\text { Loam, artificial stacking,loess, garbage, silted soil, clay, } \\
\text { silty/sandy clay }\end{array}$ & 30 \\
\hline
\end{tabular}

\subsubsection{Geomorphic types}

Geomorphologic type is one of the internal factors to control the occurrence and development of soil erosion[14].The geomorphic type controls the formation and distribution of soil medium and topographic slope .The main geomorphologic types in the study area include hills, dendritic gullies, valley plains, undulating high plains, lakeside beaches, and semi-flowing dunes. According to field investigation and previous studies, corresponding scores were assigned to geomorphic types (table 3 ).

Table 3 .Grading and scoring criteria for geomorphic types

\begin{tabular}{cc}
\hline Type & Rating standards \\
\hline Hills & 70 \\
Dendritic gullies & 60 \\
Flowing and semi-flowing dunes & 40 \\
Undulating high plains & 30 \\
Lakeside beaches & 20 \\
Valley plains & 20 \\
\hline
\end{tabular}

\subsubsection{Topographic slope}


Previous studies have shown that both soil erosion modulus and erosion amount increase first and then decrease with the increase of topographic slope[14].This time,the dem image with $30 * 30$ spatial resolution is used as the data source, to extract the slope distribution map of the study area. According to the distribution range of topographic slope, the classification is carried out according to the above rules, as shown in table 4 .

Table 4. Grading and scoring criteria for topographic slope

\begin{tabular}{cc}
\hline Slope $\left({ }^{\circ}\right)$ & Rating standards \\
\hline$>35$ & 45 \\
$30 \sim 35$ & 75 \\
$15 \sim 30$ & 100 \\
$10 \sim 15$ & 75 \\
$5 \sim 10$ & 45 \\
$0 \sim 5$ & 10 \\
\hline
\end{tabular}

\subsubsection{Land use type}

Land use types determine the types and forms of surface covers, surface coverings produce biological, physical, and chemical operations through the upper and lower spaces, and thus resist erosion[15].Different land use types also have different influence on regional hydrological process and sediment yield[16].Based on remote sensing interpretation, land use in the research area was divided, and corresponding scores were assigned according to vegetation coverage rate and artificial influence degree of different land use types. The results are shown in table 5.

Table 5. Land use type scoring criteria

\begin{tabular}{cc}
\hline Type & $\begin{array}{c}\text { Rating } \\
\text { standards }\end{array}$ \\
\hline Sandy land & 100 \\
Agricultural land & 65 \\
Unused land & 60 \\
Artificial grassland, natural & 25 \\
grassland & \\
Natural forest land, & 20 \\
artificial forest land & \\
Urban villages, industrial & 10 \\
and mining land & \\
territorial waters & 0 \\
\hline
\end{tabular}

\subsection{Factor weight calculation}

The AHP method preliminarily determines the relative importance of each factor in the hierarchical model through pairwise comparison. The order of weight is determined synthetically by means of geometric mean method. Then, the result is feasible after consistency test. The weight values of the five evaluation factors were calculated according to the AHP method, as shown in table 6 .

Table 6. The weight table of evaluation factors

\begin{tabular}{cc}
\hline Evaluation factor & Weight $(\mathrm{w})$ \\
\hline Soil medium & 0.463
\end{tabular}

\begin{tabular}{cc} 
Slope & 0.268 \\
Vegetation coverage & 0.144 \\
Geomorphic types & 0.079 \\
Land use type & 0.046 \\
\hline
\end{tabular}

\subsection{Evaluation of soil erosion sensitivity}

In this study, the comprehensive evaluation index of soil erosion EQ was introduced to evaluate the sensitivity of soil erosion. The comprehensive evaluation index is defined as the sum of various evaluation factors on a unit to the risk of soil erosion. EQ can be described as the following formula: $E Q=\sum_{i=1}^{n} I_{i j} W_{i}(1)$.

EQ: Comprehensive index of soil erosion intensity. $\mathrm{n}$ : $\mathrm{N}$ factor layers. Iij: The score value of factor layer $\mathrm{j}$ of factor layer i. Wi: The weight of the factor layer $\mathrm{i}$.

\subsection{Evaluation results}

In this research, the risk of soil and water loss was divided into five grades: no risk zone, mild risk zone, moderate risk zone, relatively strong risk zone and intensity risk zone. ArcGIS was used to divide the sensitivity level of soil erosion in the study area, and the distribution map of soil erosion sensitivity in the study area was obtained (figure 1).

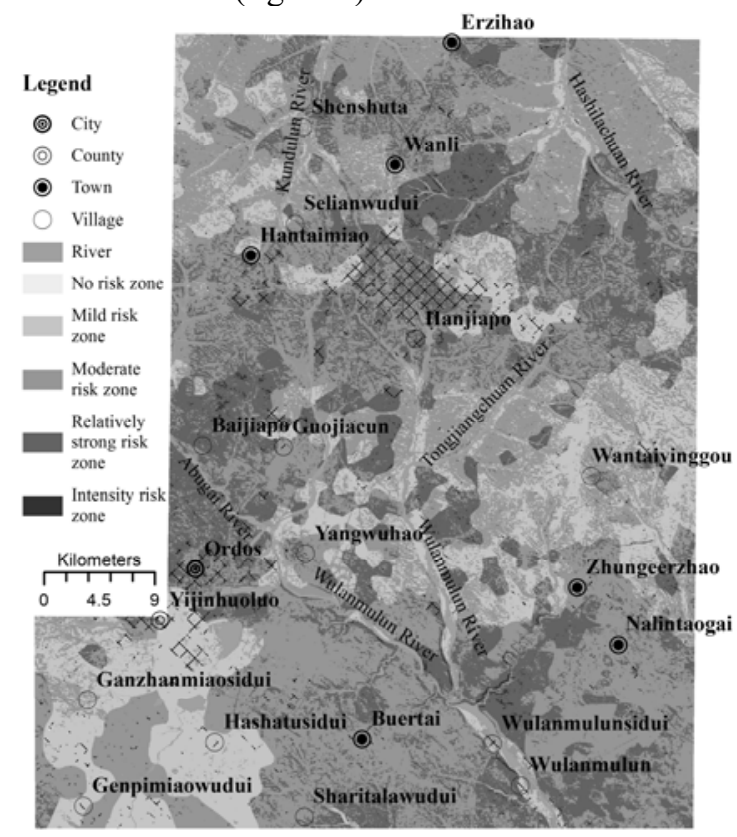

FIG 1. The soil erosion sensitivity zone

As can be seen from figure 1, different sensitivity zones of soil erosion occur in the region: moderate risk zone $>$ relatively strong risk zone $>$ mild risk zone $>$ intensity risk zone $>$ no risk zone.

The area of no risk zone is very small, scattered around Haolaisandui. The soil medium in this area is mainly loam and farmland, and soil erosion is not easy to occur. The mild risk zone is mainly distributed in the southwestern corner, northwestern corner and middle part of the research area, and a few area are distributed along rivers, the area ratio is $19 \%$ of the whole area. The soil medium in the mild risk zone is mainly loam, clay 
and coarse sand. The vegetation coverage in this region is relatively high, generally reaching about $50 \% \sim 70 \%$. The moderate risk zone is widely distributed, about $54 \%$ of the study area. The soil medium in this area is mainly silty sand, fine sand and yellow sand, mainly distributed in natural grassland, and the vegetation coverage is about $30 \% \sim 50 \%$. The distribution of relatively strong risk zone is more scattered, is mainly distributed in the south Wulanmulunsidui area, in the west Baijiapo area, and near the town of wanli in the north, the area of this zone is about $26 \%$ of the study area. Soil medium of this zone is mainly yellow sand, sandy soil and aeolian sand, which is easy to cause soil and water loss . The distribution of intensity risk zone is very small, and is mainly located in the upper reaches of the Wulanmulun river, Abugai river and a small part of the lower reaches of the Hashilachuan river.

\section{Conclusion}

At present, the AHP method was widely used to carry out the evaluation of the soil erosion sensitivity. Compared with the previous evaluation of fixed weight factors, the AHP method has the advantage of obtaining factor weights by systematically comparing the relations among factors, so that the evaluation results based on AHP method are closer to the actual conditions of the research area .The evaluation results, showed that the soil medium, slope and vegetation coverage have the highest influence on soil erosion under the same climatic and meteorological conditions in the northeast of Ordos basin. Therefore, in order to reduce soil erosion, soil improvement, land improvement, planting windproof ,sand-fixing vegetation and other measures should be adopted in the intensity risk zone. In other areas, due to the stable nature of soil medium, which is hard to change in a short period, the vegetation coverage rate can be appropriately increased. With the strengthening of ecological and environmental protection policies, the increasing trend of soil erosion in Ordos area will be greatly reversed. In general, the soil and water loss in the study area is easy to occur, and some measures should be taken to improve and protect it. It is recommended that the vegetation suitable for soil and water conservation should be planted to improve vegetation coverage and reduce soil erosion in the region.

\section{Acknowledgement}

This work was supported by Geological Survey Program of China Geological Survey (DD20190338 and DD20160130).

\section{References}

1. Zhang Tianfu, Zhang Yun, Miao Peisen,etc. Study on the chemical index of alteration of the Middle and Late Jurassic Strata in the western margin of Ordos basin and its implications [J]. Geological Survey and Research, 2018, 41 (4) :258 -262.

2. Feng Xiaoxi,Teng Xueming, He Youyu. Preliminary discussions on the metallogenesis of the Dongsheng uranium ore fields in the Ordos basin [J] Geological
Survey and Research, 2019, 42 (2) :96-108.

3. Zhao Chunguang, Li Haiguang. Effect of seabuckthorn on soil erosion in Ordos City $[\mathrm{J}]$.Geography and Environment, 2015, (12): 300-300,139.

4. Tu Xiaoning, Xu Shuangmin, Zhao Xueming, etc.Practices and reflections on recovery of coal mining subsidence area in Ordos by seabuckthorn plantation.China Water Resources,2018.21:10-12.

5. Ma Laichun, Zhang Xiaoyun. Discussion on soil and water loss control measures of Yellow River sand source area in Ordos City, Inner Mongolia [J]. Inner Mongolia Water Resources, 2012, 2 (126): 84.

6. Sui Lihua.In Coal Mine Development Soil Erosion Monitor Research Take the South Mining Area of Erdos as an Example.Yinshan Academic Journal, 2009.3 (23): 56-60.

7. Yu Xuan.Discussion on the role of achnatherum splendens in soil erosion control in ordos city[J].Inner Mongolia water conservancy,2015.1:68-69.

8. Ji Hui, Jia Xiaolan, Jia Mingliang.Application of PAM in soil erosion control in the soft sandstone area of ordos city[J].Inner Mongolia water conservancy,2016.12:29-30.

9. Liu Ruixia, Xi Rong, Meng Qingdong,etc.A brief analysis of the current situation of man-made soil and water loss in industrial and industrial parks in ordos city[J].Inner Mongolia water conservancy,2015,6:44-45.

10. Ren Hongliang, Yu Xuan, Mao Mingyue,etc.Countermeasures for preventing and controlling soil erosion in Ordos City.Inner Mongolia water conservancy,2004,4:51-52.

11. Deng Yihui,Wang Yu,Ma Song.The Application of Sub-level Analysis of Business Outsourcing in Contractor Selection[J].Hubei Today,2012,(3):43-44.

12. Li Xinwang, Zhang Zhitao, Zhang Xuepei.Proneness Evaluation Index System of Soil and Water Loss in the North China Plain based on PSR Model[J].South-to-North Water Transfers and Water Science \& Technology,2013,B02:283-285.

13. Wang Limin, Weng Boqi, Luo Tao,etc.Influenceing Factors and Mechanisms of Soil Erosion in Mountainous Areas.Journal of Anhui Agri.Sci.2016,44(19):70-75.

14. Yao Qinying.Relationship between soil erosion and geomorphology[J].Forestry and Environmental Science, 1979,4.

15. Li Keyan.Study on Characteristics of Soil and Water Loss of Different Land Use Types in Hilly Region of Eastern Liaoning[J].Jilin Water Resources, 2018,03:49-52.

16. Yan Shengjun,Guo Qingxia,Yan rui,etc.Relationship of Rainfall Intensity and the Characteristics of Soil and Water Erosion Under Different Land Use Types[J].Journal of Soil and Water Conservation,2015,2(29):45-49. 